Bí-grafia: Escritos sobre la Biología y su Enseñanza Vol. 5 No 9. Monográfico de Evolución. ISSN 2027-1034. Julio a Diciembre del 2012 P. p.89-97.

\title{
FOSILIZ-ARTE: UNA EXPERIENCIA EN EL MUNICIPIO DE FLORESTA (BOYACÁ) A TRAVÉS DEL RECONOCIMIENTO DE LOS FÓSILES Y EL ARTE COMO ESTRATEGIA DE APRENDIZAJE
}

\author{
FOSSILS ART WORK: AN EXPERIENCE IN FLORESTA (BOYACÁ)TOWN \\ THROUGH FOSSILS AND ART RECOGNITION AS A LEARNING STRATEGY
}

\section{Por: Laura Patricia López Piñeros ${ }^{1}$}

Recibido: 09-11-2012

Aceptado: 26-12-2012

\section{Resumen}

La presente crónica, narra la experiencia pedagógica en el municipio de Floresta Boyacá con los niños de tercero del colegio Héctor Julio Rangel Quintero por medio del arte como estrategia de aprendizaje en la enseñanza de los fósiles, empezando el día tres de mayo de 2012, con la contextualización de sus habitantes, su territorio, sus saberes y sus dinámicas socioculturales. A partir de esta primera visita, se dio pie a la continuidad de una segunda, los días cuatro y cinco de junio del 2012 para la realización de la práctica educativa como maestras y maestros en formación. Conforme a la elaboración del diseño de clase teniendo como eje central la mirada del arte, se quiso promover el gusto, la espontaneidad, la creatividad y el trabajo en equipo de los niños, por medio del cuento, el dibujo, el color y el moldeamiento en greda, a medida que reconocían el patrimonio paleobiológico de su maravilloso municipio. De esta manera, se observa que a partir de la vinculación del arte en la escuela, se pueden conseguir en los niños aprendizajes significativos para fortalecer el reconocimiento de su identidad.

Palabras clave: Arte, enseñanza, Floresta, fósiles, patrimonio.

\section{Abstract}

This chronicle narrates the pedagogical experience in the town of Floresta Boyacá with the children of third grade in Hector Julio Rangel Quintero school through art as a learning strategy for fossils teaching, starting from May $3^{\text {rd }} 2012$, with the contextualization of its inhabitants, territory, knowledge and sociocultural dynamics. From the first visit, it was possible to have a second one, on fourth and fifth June 2012 as part of undergraduate teachers' practicum. According to the lesson plan, which took the art as a the main concern, it aimed to promote delight, spontaneity, creativity and the group work for children, by means of the story, drawing, color and pottery, at the same time that they recognized the paleobiological heritage of their wonderful town. In

\footnotetext{
1 Universidad Pedagógica Nacional. Facultad de Ciencia y Tecnología. Estudiante de Licenciatura en Biología. Quinto Semestre. Correo electrónico: lauril11@hotmail.com
} 
this way, it is observed that from the linkage of art in the school, meaningful learning can be achieved by the children in order to reinforce the recognition of their identity.

Keywords: Art, teaching, Floresta, fossils, heritage.

Colombia se caracteriza por ser un país megadiverso que cuenta con pluralidad de etnias: blancas, afrodescendientes, mestizas, mulatas, atravesado por el legado de nuestras raíces indígenas fascinantes de mitos, leyendas y amor por la madre tierra. Esta tierra natal Ilena de historias prehistóricas, que han dejado para nosotros, bajo fértiles rocas, espectaculares registros de plantas y animales de hace miles de millones de años que cobran vida en el presente y permiten así el reconocimiento del patrimonio natural colombiano.

Es entonces cuando deslumbra un municipio que ha sido nombrado como uno de los más lindos de Boyacá, fundado el 8 de diciembre de 1818, el cual cuenta con cerca de cinco mil habitantes, con una extensión de $85 \mathrm{~km}^{2}$, una altitud de $2500 \mathrm{msnm}$ y una temperatura promedio de $16^{\circ} \mathrm{C}$, reconocido como sitio turístico en fiestas tradicionales del año, además por la fabricación artesanal de alpargatas o particulares trilobites hechos en madera y resinas, que memoran así la historia paleontológica de este lugar.

Floresta está ubicada en la cordillera oriental. Es un lugar no muy extenso, tranquilo, de gente amable, habitado en su mayoría por infantes y adultos mayores, ya que las dinámicas del lugar han llevado a que los y las jóvenes decidan, por razones de trabajo o estudio, trasladarse a la ciudad en búsqueda de otras oportunidades. El municipio cuenta con la Institución Educativa Héctor Julio Rangel Quintero, dividida en dos sedes: una para básica primaria y frente a esta, una para la sección de bachillerato. Así mismo, sus amplias casas presentan un toque colonial que la hacen atractiva para los que deseen visitarla. Por la existencia en su territorio de un pájaro llamado jaqueco, cuyo pecho es de color amarillo, se les apoda a los habitantes bucheamarillos. Se les conoce por cultivar uchuva, maíz, uva, mora, y papa, así como por hacer sus distintivas empanadas de mora y colaciones de maíz.

La importancia de sus yacimientos fosilíferos como La Loma, El Salitre, Mirador de Oriente, el Pozo de la Hormiga, Monticelo y Potreritos, reside en que entre los cúmulos de formaciones rocosas se halla la evidencia fiel de que Floresta fue un extenso mar donde había plantas y animales de diversas formas y tamaños, pero, por causas naturales, gradualmente las condiciones ambientales fueron cambiando, causando que la tierra se secara y que la variedad de especies se fosilizara en ese fondo marino.

Cuando se habla de fósiles, instintivamente y como en un gran salto a través del tiempo se tiende a pensar en dinosaurios, esas criaturas enormes que como el Tyrannosaurus rex, a partir de análisis científicos, nos han permitido identificarlos como temerarios carnívoros. Pero para sorpresa nuestra, no solo ellos han marcado la historia de nuestros antepasados y su gran tamaño no es razón para nuestro asombro, pues claramente los yacimientos ubicados en Floresta se destacan por los fósiles datados de la era paleozoica, como, trilobites (Pertenecientes al filo arthropoda. Fueron reptadores que toman su nombre de la división de la superficie dorsal de su 
cuerpo en tres segmentos longitudinales. Levin (2003)), braquiópodos (caracterizados por presentar un par de valvas que juntas constituyen la concha del animal. "Aún se pueden encontrar en los mares actuales pero en número menor que durante el paleozoico" Levin (2003)), crinoideos ("del filo Echinodermata. Compuestos de tres partes principales; el cáliz que contiene los órganos vitales, los brazos y el tallo con una raíz de fijación" Levin (2003)), corales rugosos y corales cuerno, gasterópodos (caracoles marinos) y briozoos (animales musgo. Pequeños animales que crecen en colonias), tan importantes dentro del reconocimiento del territorio como parte del proceso de formación que ha tomado muchos años y muchas vidas, y en el que las huellas de los antepasados forman parte de la identidad en los saberes que la comunidad debe fortalecer para la conservación de su patrimonio.

Entre sus dinámicas sociales y a pocos metros del parque central, epicentro de juegos de los niños después de clases o donde los abuelos se sientan a tomar el sol, se aprecian las tiendas de mercado, droguerías, cacharrerías, misceláneas, cafeterías, la alcaldía, la calle de las cotizas, el centro de salud, la iglesia principal (en la cual se hace misa todos los días, con buena confluencia de creyentes) y la casa de la cultura. En esta última se encuentra la emisora comunitaria, la biblioteca municipal, el museo paleontológico y algunas obras artísticas elaboradas en los talleres de dibujo, a los que asisten niños que con el apoyo económico de sus padres pueden sustentar la compra de materiales y pago del curso.

Respecto al museo, a pesar de no ser muy amplio, sí permite evidenciar la diversidad de fósiles que se hallan en el municipio y que con el apoyo de Ingeominas (Instituto Colombiano de Geología y Minería), se ha llevado a cabo su identificación, así como la vinculación progresiva de estos saberes con la escuela y la comunidad, que poco a poco va haciéndose visible a la mirada evolutiva de este patrimonio.

De esta manera, a partir de la contextualización realizada en el municipio de Floresta, los días tres, cuatro y cinco de mayo del 2012 como maestros y maestras en formación de la Universidad Pedagógica Nacional de Bogotá parte del eje curricular Organización y con el acompañamiento de nuestros maestros, se evidenció que entre los habitantes de Floresta se desconoce parcialmente la riqueza fosilífera y su importancia evolutiva, conforme al primer acercamiento; más aún en el aula de clase cuando los niños reconocen con claridad la ubicación geográfica de los yacimientos, pero en sí no identifican los fósiles que se encuentran en ellas, viendo estas evidencias como interesantes rocas con formas y figuras sin llegar a fascinarse por el conocimiento de nuestros ancestros en la Tierra.

Acorde a la práctica pedagógica que se realiza en los diferentes semestres de la Licenciatura en Biología y de acuerdo al presente proyecto, enfocado en el arte como estrategia que favorece mejores aprendizajes en los estudiantes, se interactúa con los niños de tercer grado del colegio Héctor Julio Rangel Quintero para conocer a priori, por medio de dos dibujos, lo que significa para cada uno de ellos su territorio y así mismo sus saberes acerca de lo que son los fósiles. Cada estudiante tomó lápiz y papel para comenzar a dibujar. Se observó en ellos el gusto por esta clase de 
actividades artísticas, que favorecen ampliar la mirada de los procesos educativos y que no solo se encaminan en las praxis de lectoescritura, sumergiendo la perspectiva de los maestros en diferentes metodologías de enseñanza.

Desde el momento en que se les propuso la actividad cada niño se esmeró por entregar un buen resultado, hasta tomaron su tiempo para retocar sus imágenes y así mismo conseguir prestados colores y pintarlos. En el primer dibujo la mayoría de los niños plasmó casas, animales, montañas y algunos de ellos a su familia. Ya para el reconocimiento de las nociones que tienen sobre fósiles, de los veintiocho niños se obtuvo que diecisiete de ellos no saben lo que es un fósil, pero once de ellos dibujaron a su manera los registros que han encontrado, indicando los nombres de algunos yacimientos como son el Pozo de la Hormiga y La Loma que les resultan más familiares a la mayoría y con lo cual al momento de explicar sus esbozos a la clase, varios daban rienda suelta a contar cómo y dónde hallaron estas evidencias, con la claridad de que su territorio había sido hace muchos miles de años un extenso mar con diversidad de organismos, mientras algunos compañeros absortos en estas historias escuchaban por vez primera la palabra fósil, exponiendo sus deseos de aprender más sobre ellos. Además, al hablar con la profesora a cargo de este grupo de estudiantes, manifestó su desconocimiento sobre el tema, sin dejar de lado el interés por familiarizarse con estos saberes que le permitan así señalar desde sus prácticas educativas, la importancia por el territorio.

A partir de estas interacciones con los niños y la profesora a cargo del grupo de estudiantes, se apreció como se ha distanciado el contexto en los procesos de enseñanza de la institución, ya que al tener un enfoque en la formación técnica con especialidad en electricidad y comercio, se aleja de las necesidades de la región.

Es así como este primer acercamiento al municipio nos incentivó, como maestros en formación, a buscar estrategias que permitieran promover el interés en los niños, para apropiarlos de los saberes y conocimientos a cerca de los fósiles y el valor paleobiológico de los mismos en la historia evolutiva, resaltando así el papel significativo del arte en los procesos educativos desde las experiencias empíricas de los niños con su entorno, para que continuamente vinculen a familiares, amigos, maestros y vecinos con las riquezas de saberes, con miras a fortalecer su identidad.

Hecha la contextualización en Floresta, se articula desde el proyecto llamado Fosilizarte un diseño de clase pensado en los niños de tercer grado del colegio Héctor Julio Rangel Quintero, que impulse las capacidades motrices y creativas desde el trabajo en equipo con sus compañeros. Se decide salir de las convencionales aulas donde se enseña y hacer la clase en el parque central, visibilizando la escuela, la paleontología y la comunidad, proponiendo como apertura un cuento, seguido por la ilustración de los grupos fósiles que se hallan en el territorio, continuando con las manualidades en greda a ser expuestas en la feria del fósil y retroalimentando a modo evaluativo la posterior identificación de registros que hallarían en un yacimiento (para este caso se haría una montaña en papel kraft). Teniendo presente que la disposición 
en tiempo correspondía a dos bloques de clase, es decir unos noventa minutos o incluso dos horas, se asignaron de la mejor manera los lapsos para cada actividad.

De esta manera, en la segunda visita para la puesta en práctica del diseño de clase el día cinco de Junio de 2012, se organizan hacia las siete de la mañana, en el parque central, varios estantes con algunos fósiles prestados por el museo para la actividad, así como pósters alusivos al tema y, roca a roca, se va dando forma al yacimiento en papel kraft. Al momento en que se ingresó al aula y los niños vieron que habíamos regresado a enseñarles sobre los fósiles, gritaban de alegría al unísono ante nuestra sorpresa. Niños con deseos de conocimiento que afectuosamente recibían nuestro retorno, entusiasmando los procesos del ser maestro. En fila nos encaminamos al parque central, el cual se encuentra a pocas cuadras de la institución, y a medida que llegaban los niños se hizo una rueda para comenzar la clase. Se convidó a la profesora que se encontraba con los niños para que participara en el conjunto de la dinámica, pero ella prefirió no asistir.

Se inicia con una historia en la que hace muchísimo tiempo un trilobite se movía ágilmente en el fondo del mar, atravesando un arrecife coralino en busca de alimento mientras dialogaba con sus amigos crinoideo y braquiópodo por la posible ubicación de su amigo colonial don briozoo (...). Con el anterior cuento se logró la atención de los niños, sorprendidos por el final de la historia. Al preguntarles cómo creían que eran los crinoideos, los gasterópodos, los briozoos, los cnidarios o los braquiópodos, algunos contestaban que se imaginaban a los trilobites y a los crinoideos grandes y a los braquiópodos y los briozoos pequeños; en cambio otros niños suponían que todos ellos habían sido muy grandes.

Se les explicaron a los niños los cinco grandes grupos de fósiles anteriormente nombrados que se encuentran en Floresta, de forma que pudiesen aprender y retroalimentar con sus preguntas.

Se organizaron cinco equipos de trabajo con los niños y a cada grupo se le dio greda, palillos y papel periódico, con el apoyo en la orientación artística de una maestra en formación. Fue así como el arte invadió el espacio del parque central, donde cada niño moldeó desde su percepción lo que conocemos como fósiles. Algunos se entusiasmaban tanto que hacían tres o cuatro figuras en arcilla, las comparaban con sus compañeros y con las que nosotras mismas hacíamos.

Gracias al tiempo soleado se fueron secando las réplicas que poco a poco fueron colocándose sobre los estantes para que iniciara la tan anhelada feria, en la que se exponían algunos fósiles del museo y los elaborados por los niños. Solo hacían falta las personas, pero esto no fue problema porque con la ayuda de los niños se fueron acercando: adultos, ancianos, jóvenes y padres de familia a los que ellos iban contando sobre sus creaciones en greda y algunas características morfológicas de las que recordaban de lo anteriormente enseñado. Las personas que por allí pasaban a visitar la feria escuchaban atentos a los niños mientras ellos, entre tímidos y valientes, daban sentido a la exhibición. Incluso una señora comentó que su nieto tiene en casa 
sobre una mesita que él mismo organizó, varios fósiles que se ha encontrado en La Loma y Potreritos.

Conforme a los acercamientos de los niños con los fósiles prestados por el museo, las manualidades sobre greda y las enseñanzas recibidas, se procedió a hacer la evaluación, la cual consistía en buscar fósiles en un yacimiento artificial hecho de papel que simulara formaciones rocosas, lo que permitía enseñarles cómo buscar fósiles sin tener que perjudicar evidencia importante. Los niños se emocionaron tanto que la actividad no salió como se esperaba, pues se lanzaron a la búsqueda compitiendo por el que más encontrara, sin tener presente el cuidado que se ha de tener en la exploración de estos. A pesar de la prisa en la dinámica, al momento de preguntarles cómo se llamaban los fósiles que tenían en sus manos, los niños lograban identificarlos; algunos recordaban los nombres y decían claramente "lirios de mar"; otros titubeaban las primeras letras y otros lo asociaban con lo que se plasmaba en los pósters, señalándolos o indicando entre ellos los fósiles que se les asemejaban. Cabe resaltar que al final de la actividad evaluativa se aclaró a los niños que de esta manera no se debía buscar en un yacimiento, diciéndoles los cuidados a tener para evitar la destrucción de evidencias importantes.

Se cumplen los tiempos indicados para el diseño de clase. La labor realizada con los niños satisface las expectativas, permite dar cuenta de que se aprende de ellos en las interacciones propias de la enseñanza dentro y fuera de la escuela y que el arte cobra significado en la educación, por ser una actividad dinámica y unificadora. El dibujo, la pintura o la construcción permite a los niños reunir diversos elementos de su experiencia para formar un todo con un nuevo significado. En el proceso de seleccionar, interpretar y transformar esos elementos, los niños nos dan algo más que un dibujo o una escultura; nos proporcionan una parte de sí mismos; cómo piensan, cómo sienten y cómo ven. (Lowenfeld 1980).

Con la intención de que los niños conocieran más de su territorio, y aunque el tiempo establecido para la clase había terminado, se acordó con ellos encontrarnos nuevamente después del horario establecido de clases para visitar el museo en compañía de su profesora. Los niños colocaron sus conocimientos previos de la clase en práctica y fácilmente eran capaces de identificar las muestras de fósiles que se observaban en el museo. Claro que al nombrarlos era fácil que dijeran algo como crinobites, o como crino (...) y no recordasen claramente el nombre del grupo correspondiente, tal como les sucedió en el proceso evaluativo.

Ver sus rostros de satisfacción por los fósiles del museo es uno de los más grandes recuerdos del hermoso interactuar con los niños de Floresta. Además, es la alegría tras un abrazo, un juego compartido, un tiempo de escucha, un nombre que les recuerde, un aprendizaje, una sonrisa en el camino. Es una experiencia que va más allá de las palabras.

Gracias al museo, los estudiantes, la maestra y la comunidad, se permitió que la clase no solo se quedara en un aula sino que trascendiera al pueblo, fortaleciendo el 
reconocimiento del patrimonio paleontológico y sociocultural. Así mismo, se evidenciaron debilidades que como maestra en formación se tienen a la hora de enseñar y que deben corregirse para mejorar en el camino. Cabe decir que este acercamiento pedagógico permitió la realización de un encuentro programado con las directivas de Floresta, de forma que se dialogara desde nuestros acercamientos en la praxis educativa y social sobre algunas miradas de apropiamiento por parte de los habitantes (niños, ancianos y adultos) de su territorio, mostrando que reconocen la ubicación geográfica de los yacimientos, pero que presentan un parcial desconocimiento de los fósiles, tan importantes en este contexto, y que desde la misma escuela los programas curriculares son ajenos a estos registros que permean en la cotidianidad de sus vidas.

La posibilidad de dialogar con las directivas del municipio favoreció que desde nuestros acercamientos en la praxis educativa y social, se dieran a conocer algunas falencias respecto a las dinámicas de apropiación del patrimonio, evidenciando que la comunidad no se vincula al reconocimiento de fósiles en los respectivos yacimientos, a pesar de que sí se ubican geográficamente en estos. Cuando se habla con maestros, estudiantes y demás habitantes, admiten en su gran mayoría desconocer lo que son los fósiles, de gran importancia dentro de su contexto, y que en la escuela se encuentran ajenos al programa curricular, por lo que como Universidad Pedagógica Nacional se percibió la necesidad de apoyar a los maestros en su práctica educativa y así mismo a las directivas, para que reevaluaran la importancia de invertir en educación y en los habitantes florestanos.

Don Luis Becerra, artesano, ebanista, habitante del corregimiento de Tobasía (municipio de Floresta ubicado a tres kilómetros de éste), quien se ha interesado desde hace algunos años por la paleontología del municipio y es un entusiasmado porque la comunidad se apropie de su territorio, expone ante las directivas municipales que en los aspectos legales se han presentado muchos vacíos y se necesita una reglamentación que brinde protección al patrimonio.

Ante todo lo anteriormente comentado, el rector del colegio de Floresta toma la palabra, denotando que falta entrelazar el conocimiento con la riqueza cultural en el currículo de ciencias, pero que la responsabilidad mayor de la institución es cumplir con los estándares nacionales -por la aplicación de las pruebas saber-, con lo cual se da a los niños es un conocimiento general, mas no específico de su territorio.

Buscando posibilidades que mejoren las dinámicas educativas a partir de la contextualización realizada por parte de la Universidad, se presenta un proyecto que permita fortalecer el sentido de pertenencia de los florestanos para con el territorio. Se propone el presente: Identidad y reconocimiento mediante procesos educativos, en el que se tiene como objetivo caracterizar las concepciones de los estudiantes, profesores y comunidad sobre territorio, además de brindar asesoramiento a los profesores en el diseño curricular de educación y capacitarlos por un programa virtual, mediante un diplomado y procesos de enseñanza convencional con salidas de campo, entrega de material identificado y documentado, proyectando que las prácticas 
pedagógicas se vinculen con las líneas de investigación de Bogotá. Se propone solicitar apoyo paleobiológico y paleontológico a Ingeominas, ya que ellos son pioneros en el tema.

En respuesta, el alcalde agradece nuestro interés por el municipio. Habla de un espacio físico de $1500 \mathrm{~m}^{2}$ que en este momento está ocupado en cosas no beneficiosas para el municipio, pero espera la aprobación de ese terreno para la adecuación del museo, a la cual da como plazo tres años, correspondientes a la culminación de su alcaldía, para lograr este fin. Además, asegura estar a disposición de aceptar nuestro apoyo y ve la necesidad de recibir direccionamiento de parte de Ingeominas para la adecuación del museo.

Con las diferentes intervenciones realizadas se cierra la cesión, retomando los puntos clave de la reunión con el ánimo de, primero, dar apertura a la convocatoria de grupos de investigación supeditados a trabajar y estudiar en el territorio, y de parte de las directivas de Floresta (alcalde, concejales) se hace el compromiso para la inversión y adecuación de la infraestructura del museo paleontológico, aceptando la colaboración de Ingeominas para la clasificación de los fósiles hallados en la región; en segundo lugar, de buscar los medios para patrocinar a los docentes en el diplomado que les ofrece la Universidad; y tercero, darle continuidad al proceso educativo y al estudio paleobiológico por parte de los estudiantes del Departamento de Biología, que en las salidas de campo seguirán estudiando los procesos en el municipio.

Es por esto que la educación resulta importante para los procesos de aprendizaje conforme a la apropiación social y participación ciudadana, de manera que desde las primeras etapas de formación, los niños establezcan la importancia que presenta la conservación del patrimonio de Floresta con los yacimientos fosilíferos que allí se encuentran.

Fue así como desde la reflexión en las dinámicas educativas, en un par de meses desde el día de nuestra visita se organizó una reunión conjunta entre Ingeominas y los entes gubernamentales del municipio, donde se evaluó el lugar y las posibles fechas para la adecuación del museo, como parte de un proyecto en movimiento para que dé verdaderos frutos.

Debo decir que gracias al apoyo siempre fiel de don Luis Becerra a este bello lugar, una persona interesada por aprender más sobre este municipio y por hacer del museo un espacio de conocimiento, fue posible nuestra contextualización en el territorio, pues con sus saberes empíricos demostró que siempre es posible fortalecer la enseñanza desde la identidad del contexto en el cual se vive, y que perseverando por lo que se quiere se pueden lograr grandes cambios. Así mismo, agradezco a Marie Joelle Giraud, ingeniera geóloga de Ingeominas, que con su carisma y pasión por los fósiles, por el municipio de Floresta, por los aprendizajes y saberes de niños y adultos del territorio, motivó nuestra práctica pedagógica y biológica siendo nuestro fiel apoyo en este aprendizaje. También al equipo de maestros de cuarto semestre, quienes con su constancia permitieron esta experiencia educativa y humana. Por último, y no por ser 
menos importantes, a los niños y habitantes de Floresta, que con su disposición dieron paso al reconocimiento de lo que nos han dejado nuestros ancestros hace millones de años escondido en las entrañas de la tierra, preservando diferentes organismos marinos que reinaban en mares del paleozoico, y que hoy hacen parte de los saberes sobre el desarrollo de lo que somos.

\section{Referencias}

Floresta. Boyacá (2011). Recuperado de http://www.floresta-boyaca.gov.co

Institución educativa Héctor Julio Rangel Quintero (s.f.). Recuperado el día 24 de abril de 2012 de http://www.colfloresta.8m.com

Levin, $\mathrm{H}$ (2003). The earth trough time. $7^{\text {th }}$ Edition. Wiley publishing. New York.

López, L (2012). Cuaderno de campo. Cuarto semestre. Manuscrito no publicado. Universidad Pedagógica Nacional. Bogotá. Colombia.

Lowenfeld, V (1980). Desarrollo de la capacidad creadora. Kapelusz. Buenos Aires. Argentina.

Museo Historia Natural de Floresta, un sueño cada vez más cercano. (2009). Recuperado de http://museoparatodosfloresta.blogspot.com/ 